\title{
COVID-19 AFFECTED MENTAL HEALTH OF AT-RISK GROUPS OF PSYCHIATRIC PATIENTS: TWO CASE REPORTS
}

\author{
Nera Hodžić, Mevludin Hasanović \& Izet Pajević
}

Department of Psychiatry, University Clinical Center Tuzla, School of Medicine, University of Tuzla, Tuzla, Bosnia and Herzegovina

received: 29.5.2020;

\author{
revised: 3.6.2020;
}

accepted: 10.6 .2020

\section{INTRODUCTION}

The world is in the midst of the COVID-19 pandemic, emerging huge global geopolitical changes and possibly pandemic of mental disorders (Jakovljević 2020). It is quite clear that the COVID-19 pandemic affects not only physical health, but also mental health and individual and collective behavior and way of life changing priorities and challenging health care system functioning (Fiorillo \& Gorwood 2020). The COVID-19 pandemic represents very complex events, complex in its origin, its spread, its effects and its consequences at multiple levels and fields; medical, social, political, economic, religious, cultural and civilizational (Jakovljevic et al. 2020). Due to COVID-19 pandemic many people are afraid, anxious, in panic, angry, uncertain, depressed, and without confidence in their national leadership (Jakovljevic et al. 2020). Fear responses in both the uninfected and infected may reach psychopathological levels that require psychiatric interventions (Duan \& Zhu 2020). Of particular importance is the psychological potential that pandemic can have to exacerbate existing psychiatric conditions and influence the manifestation of their symptomatology. Psychic reaction can be considered as the output of a process that emphasizes the "dark side" of virus pandemic, integrating the unconscious and fantasies with conscious contents (Marčinko et al. 2020). However, media has underlined COVID-19 as rather an exclusive threat, which has added to panic and stress in masses which can lead to several mental health issues like anxiety, obsessive compulsive disorder and post-traumatic stress disorder which should be contained immediately in its initial phases (Shuja et al. 2020). Though the pandemic of COVID-19 has spread fear on not only individual but societal levels and the need to implement proper mental health precautions along with physical health precautions, especially in countries like Bosnia and Herzegovina $(\mathrm{B} \& \mathrm{H})$ where resources are limited particularly after war 1992-1995 when wounds of the war were not completely healed (Hasanović \& Hasanović 2020). Though, timely detection and eradication of mental health issues can help the patients in long term sufferings (Shuja et al. 2020).

The first case of COVID-19 infection in B\&H was recorded in Banja Luka on March $5^{\text {th }} 2020$. Since then, up to $22^{\text {nd }}$ May 2020, 2372 people have been revealed with COVID-19 in B\&H, and 141 people have died (Ministry of Civil Affairs of Bosnia and Herzegovina 2020). After the proclamation of the pandemic measures, Department of Psychiatry in Tuzla, in agreement with the management of the University Clinical Center Tuzla, following the orders of the Crisis Headquarters of the Federation B\&H and Tuzla Canton, reorganized its spatial and human resources. All patients who required intensive psychiatric treatment remained at the Department of Psychiatry, and the rest were transferred to home treatment and further outpatient follow-up with recommendations for continued treatment. The Ward of Child and Adolescent Psychiatry has been turned into an isolatorium for patients who admitted on inpatient treatment. From everyone admitted patient, a nasopharyngeal swab was taken immediately and processed microbiologically. Every patient must stay in isolatorium until the result of the microbiological examination is known. Patients who tested positive for COVID-19 were scheduled to be treated at the Clinic for Infectious Diseases of the University Clinical Center Tuzla, which was turned into a COVID hospital in the conditions of a pandemic. Patients who are negative for COVID-19 are transferred to Ward of Acute Conditions and SemiIntensive Care with other inpatients on the Department of Psychatry for continual psychiatric treatment.

Given that the literature describes anxiety, obsessive-compulsive response, the development of PTSD and psychotic crises, we will present two cases of psychiatric patients who suddenly deteriorated and burned in a severe psychiatric condition due to the circumstances they faced due to the COVID-19 pandemic, which required urgent admission and intensive psychiatric treatment.

\section{CASE REPORT 1}

Male, aged 50, married, father of three children, was brought to the Department of Psychiatry accompanied by his daughter, brother and the Emergency Medical Service staff in a soporific state, after he attempted suicide by taking large amounts of psychotropic drugs. In the triage tent of the University Clinical Center Tuzla, a nasopharyngeal swab on COVID-19 from patient was taken. After admission to the Department of 
Psychiatry he stayed in the planned isolation ward until the completion of the smear test on COVID-19, which was negative, then he was transferred to Ward for Acute conditions. This is his first hospitalization in psychiatric institutions in $\mathrm{B} \& \mathrm{H}$. No pathological results was recorded on physical examination. In laboratory analysis were recorded elevated triglycerides $2.14 \mathrm{mmol} / \mathrm{L}$, cholesterol $6.84 \mathrm{mmol} / \mathrm{L}$, LDL cholesterol $4.28 \mathrm{mmol} / \mathrm{L}$ and iron $33.60 \mathrm{umol} / \mathrm{L}$, while slightly decreased hematocrit values $0.414 / \mathrm{L}$, as well as sodium $135 \mathrm{mmol} / \mathrm{L}$ and phosphate $0.82 \mathrm{mmol} / \mathrm{L}$. Other laboratory parameters of blood and biochemistry were in reference values. In the morning after admission, after stabilization the state of consciousness, with the patient a psychiatric interview was performed. The patient lives in a small town $40 \mathrm{~km}$ away from Tuzla, but has been working in one country of European Union (EU) since 2003 in a construction company. He had registered his permanent residence and health insurance in this EU country. He has been on sick leave since June 2019, after experiencing an accident at work when he was buried by the ground while working in civil engineering. He used to come home to $\mathrm{B} \& \mathrm{H}$ during his sick despite it was forbidden related to the regulation of Health Institution of that country. Ten days before the current admission, he went back to the EU country where he works to report to the competent family medicine physician (MD), who regulated his treatment and scheduled a check-up. Upon his return to $\mathrm{B} \& \mathrm{H}$, he stayed in his house in self-isolation, because the pandemic regulations started to be obliged. On the day of the admission, he called his MD by phone in order to inform her that he could not come to that country for a appointed check-up due to restricted movements because of the COVID-19 pandemic. The doctor told him: "... that he was not allowed to leave the country while he was on sick leave and she threatened him with deprivation of health insurance and dismissal (job loss)." After that conversation, the patient felt restless, helpless, saw no way out of his situation and took higher amounts of escitalopram, zolpidem and pregabalin (drugs prescribed by a competent psychiatrist in the EU country where he works).

\section{Psychiatric history}

Mental ailments date back about 20 years in the form of tension, mood swings, insomnia, loneliness, panic attacks, nightmares, while outpatient treatment for over 15 years, on therapy with antidepressants and anxiolytics. In the period from September to December 2019, he was hospitalized at the Psychiatric Clinic in the country of European Union.

\section{Psychopathology}

The mental profile is dominated by low mood, irritable affect, symptoms of chronic PTSD in the form of re-experiencing through flashbacks, symptoms of hyperarousal and avoidance, negative self-concept, disturbed interpersonal relationships, low frustration threshold and latent suicidality. There were no productive psychotic symptoms.

\section{Course of disease}

During the current psychiatric treatment, several individual psychotherapy sessions and group psychotherapies were performed. The patient refuses to disclose the traumatic content of the war, stating that he has already told most of it to his psychiatrist from abroad. As a 20-year-old, he spent four years of the war in $\mathrm{B} \& \mathrm{H}$ on the battlefield of his hometown, and after the end of the war, six years as a professional soldier in the Army of Republic of B\&H (ARBH), which he then left voluntarily after the war quitted. In the following period, due to the difficult financial situation and existential problems, he started working as a construction worker in the EU country, while his wife and daughters remained living in $\mathrm{B} \& \mathrm{H}$. $\mathrm{He}$ is dissatisfied with his status as a veteran in $\mathrm{B} \& \mathrm{H}$ and stated that he had to go abroad to save his family. He also stated that he by taking medication and attempting suicide he saw a solution to the existential problem, because his children would receive material assistance after his death and have possibility of finishing school. His biggest fear is that his children will be as hungry as he was during the war. During his stay in the professional army, he stayed in the barracks, which for 13 years was reorganized as the Department of Psychiatry of the University Clinical Center Tuzla where he has been admitted and treated actually. A few days after the admission to the Department of Psychiatry, he realized that it was the same building where he worked during his engagement in the professional army. He stated that his stay in this institution imposes the recall of images from the war and that it is difficult to deal with. During his stay in the Acute Ward he refused full cooperation, was bothered by the fact that he was in a restrictive environment, constantly compared the circumstances with his stay in psychiatric hospital abroad. He constantly expressed dissatisfaction and desire to go to his competent medical institution as soon as possible, in order to avoid sanctions for leaving EU country during his sick leave. As there was no indication for involuntary hospitalization, the patient was discharged after 12 days of treatment, under the diagnoses of Intentional self-poisoning by and exposure to antiepileptic, sedative-hypnotic, anti-parkinsonism and psychotropic drugs, not elsewhere classified X61, Recurrent Depressive Disorders F33.2 and PTSD Complex F62.0, on antidepressant therapy, atypical antipsychotics and anxiolytics (Diagnoses according the ICD 10).

\section{CASE REPORT 2}

Female patient, 51 years old, married, mother of two children, was brought to the Department of Psychiatry accompanied by two police officers and a sanitary engineer from the University Clinical Center Tuzla (UCC Tuzla) agitated, uncooperative and with rapid and 
incoherent speech. During admission, a nasopharyngeal swab for COVID-19 was taken. She stayed in the isolatorium while waiting for the result of the microbiological finding of the swab, which was negative. Physical examination did not record any pathological findings, and laboratory tests showed elevated values of leukocytes $10.51 \times 109 / \mathrm{L}$ and triglycerides $1.71 \mathrm{mmol} / \mathrm{L}$, and decreased values of AST $11 \mathrm{U} / \mathrm{L}$, urea $3.0 \mathrm{mmol} / \mathrm{L}$ and valproic acid concentrations. in serum that was $32.72 \mathrm{ug} / \mathrm{ml}$. The patient is an employee of the UCC Tuzla as a cleaner at one organizational department, which was transformed into a Clinic for infected patients with COVID-19 during the pandemic. However, our patient was on sick leave in February 2020 and returned to work at the end of the same month. When pandemic started she was assigned to the position of cleaner in the administrative part of the UCC Tuzla. On the day of the reception at work in other building, she suddenly became upset, started yelling, banging on objects and singing. At the admission, she stated that she "is not afraid of the coronavirus or anything else", that she "received a revelation from Queen Nur as well as from the Prophet Muhammad", that "we do not worry, everything will be fine, but we do not take the situation lightly". She also said that she had taken the previously recommended therapy regularly. Neither the patient nor accompaniment provided positive epidemiological information, which was subsequently obtained by telephone contact of the nurse with the patient's family. Namely, early the son of a patient who works in Croatia came home and was subjected to selfisolation. Despite this our patient visited her son despite it was forbidden, and had a coffee with him without self-protective equipment. After this event, she changed mentally and fell into aggravation of the underlying disease with psychotic symptoms.

\section{Psychiatric history}

Mental ailments date back 20 years with the onset of tension, fear, feelings of suffocation and stomach pain. She was hospitalized at the Department of Psychiatry on ten occasions through the period. The first hospitalization was in 2004 due to mood swings, apathy and suicidal thoughts. The last hospitalization was in 2016 due to high mood, altered behavior, and unrelated speech. In earlier hospitalizations, she also mentioned that she "received announcements from Queen Nur." She is diagnosed with bipolar affective disorder (BAP) with psychotic symptoms, taking antipsychotics and mood stabilizers in her therapy.

\section{Psychopathology}

The mental profile emphasizes psychomotor agitation, logorrhea, high-pitched speech, occasionally dissociated flow of thoughts, with delusions of megalomania and religious delusions. She denied perceptual deceptions and did not seem to experience them. She has had a high mood, manic affectivity, with sudden behavioral raptures and no insight into her condition.

\section{Course of disease}

During the treatment in the Acute Ward on the applied therapeutic procedures (psycho-pharmacotherapy, socio-therapy and group psychotherapy) she has been a gradually mentally stabilized. In the first days of treatment, she stated that she had a conflict with her boss, who assigned her to another job in another building, "even though she only wanted to work at the in the Department where she is regularly employed", "that they shouldn't have spared her crowns, because her crown can't nothing". In psycho-pharmacotherapy, lithium carbonate and sodium valproate are added to olanzapine, to achieve stabilization of affectivity and alleviates motor incontinence, as well as to reduce delusional content. At dismissal, she had s better insight into her condition, an orderly flow of thoughts, the symptoms of psychosis were reduced, and the affect was stabilized. Further outpatient follow-up and treatment is planned.

\section{DISCUSSION}

Being aware that the extreme social changes will result from the coronavirus pandemic and that these changes will be reflected in the ways people will be living their lives makes this all the more important (Mindoljević Drakulić \& Radman 2020). Our first patient is vitally attached to the system and the first case report is an example of the correlation between the war traumatization, economic crisis after the war, mental and social problems of economic migration, existential issues caused by COVID-19 and suicidality. The COVID-19 pandemic has led to the introduction of strong restrictive measures that are having a substantial effect on the global economy, including an increase in the unemployment rate worldwide (International Labor Organization 2020). Data from the economic crisis of 2008 showed that the increase in suicides preceded the actual rise in the unemployment rate (Nordt et al. 2015). In a study recently done by Kawahol and Nordt (2020), the expected number of job losses due to COVID-19 were taken from the International Labour Organization's press release from March 18, 2020, reporting a decline of 24.7 million jobs as a high scenario and 5.3 million jobs lost as a low scenario. In the high scenario, the worldwide unemployment rate would increase from $4.936 \%$ to $5.644 \%$, which would be associated with an increase in suicides of about 9570 per year. In the low scenario, the unemployment would increase to $5.088 \%$, associated with an increase of about 2135 suicides (Kawahol \& Nordt 2020). The downsizing of the economy and the focus of the medical system on the COVID-19 pandemic can lead to unintended long-term problems for a vulnerable group on the fringes of society (Kawahol \& Nordt 2020). Financial loss can be a problem during quarantine, with people unable to work and having to interrupt their professional activities with no advanced planning; the effects appear to be long 
lasting (Brooks et al. 2020) and can create serious socioeconomic distress (Pellecchia et al. 2015). The literature describes that suicidality among war veterans is increased (Hasanović \& Hasanović 2020). Suicide is a significant problem among military veterans in the United States (Kang et al. 2015). Suicide rates in the U.S. population as a whole have increased in the last decade (Olfson et al. 2017, U.S. Department of Veterans Affairs 2016). Bhawrday et al. (2019) have done their research on understanding the pathways between PTSD, depression, hostility, anger, and aggression. They have found out that hostility, anger and aggression are conceptually related but unique constructs found to occur more often among veterans with posttraumatic stress disorder than among civilians or veterans without PTSD. Results indicate that PTSD is not the overall direct contributor to different forms of aggression, supporting the mediating role of depression and trait anger. Depression symptoms explain part of the relationships between PTSD and verbal aggression, physical aggression toward objects, and physical aggression toward self. Wilks et al. (2019) have revealed that suicidal ideation in U.S. military veterans was positively associated with anger and negatively associated with social support.

Another important thing we want to point out through the first case is the potential danger posed by impaired doctor-patient communication. Doctor-patient communication is perhaps the most important "nonspecific" or placebo effect in medicine (Jakovljević 2014). The effectiveness of medical treatment depends on the quality of the patient-clinician relationship (McCabe \& Healy 2018). Shared understanding between doctor and patient is fundamental because it is a prerequisite for finding agreement with both the nature of the problem and the most appropriate treatment. The more closely patients and doctors can align on these two key aspects, the more likely the patient is to follow treatment recommendations and have a better longer term treatment outcome (McCabe \& Healy 2018). Our patient has repeatedly pointed out that the "rough approach" and "way of addressing" to him by family MD "who threatened him with loss of health insurance" made him feel helpless. Quality of care may also be affected by physicians' perceptions of patients. Because physicians' communication and perceptions are related to outcomes, it is critically important to account for variability in physicians' behavior as well as understand why different doctors talk and perceive different patients differently. With such an understanding, researchers and educators will be better positioned to effectively examine relationships between communication and outcomes as well as design interventions for improving the quality of health care (Street et al. 2007). On the other hand, there is a consensus in all the relevant literature that health care professionals during pandemic are at an increased risk of high levels of stress, anxiety, depression, burnout, addiction and post-traumatic stress disorder, which could have long-term psychological implications (El-Hage et al. 2020). They are also at risk of getting infected, and they carry a large burden in the clinical treatment and prevention activities in hospitals and community settings. The challenges and stress they experience could trigger different mental disorders, including anxiety and affective disorders. Indeed, some experts believe that maintaining mental health of the medical staff is necessary to better control infectious diseases, although the best approach to this during the epidemic season still remains unclear (Chen et al. 2020).

In second case report, we pointed out the potential that the crisis caused by the COVID-19 pandemic has in the precipitation of patients with bipolar affective disorder entering the manic raptus accompanied by megalomaniac delusions, disorganized behavior and speech and uncritically. Fischer et al. presented a case report that shows the impact of the COVID-19 crisis on the psychopathology of a patient with paranoid psychosis leading to the outbreak of a psychotic phase with paranoid-hallucinatory experiencing and unrealistic expectations and concerns (Fischer et al. 2020). We did not find other results on patients with bipolar disorder during the COVID-19 pandemic. The precipitating factor in our patient is certainly impaired working structure. Bipolar disorder among the working population can have a significant, negative effect on work relationships, attendance and functioning (Laxman et al. 2008). Longitudinal study done by Chang et al. (2016) about change in employment status in bipolar disorder proved that patients with bipolar disorder had poorer employment outcomes than the controls, with greater risks of occupational deterioration before and after the bipolar episodes. Our patient stated that her superiors should not have spared her of coronavirus by moving her to another job, while at the same time she did not adhering to protective measures such as wearing masks and gloves, as well as illegally violating the rules of selfisolation and going to her son's premises again without using protective equipment as ordered. But knowing that denial when people refuse to acknowledge the threatening reality is presented particularly at the beginning of crisis (Jakovljević 2020), which is also seen in this case.

As it is to be expected that there will be a range of long-term negative mental health consequences to this pandemic, psychiatrists and other mental health workers are to help their patients, their families, and the whole community to better understand and prevent mental health problems' pandemic (Shuja et al. 2020). Psychiatrists can educate and promote methods and interventions that foster positive behavioral change and solidarity. Focus on life-style medicine and psychiatry encouraging people to hope, pray, sing, dance, exercise, and use relaxation techniques to restart their brains and control their stress, anxiety, worry, and PTSD may be very efficient. These simple actions can induce in our mind and body relaxation, calmness, peace, mindfulness and strengthen resilience. Knowledge, empathy, solidarity, cooperation and unity are the key factors to long- 
term survival and flourishing of humankind. Let's hope that the war against corona disease will be followed by more successful fighting for public and global mental health with more agility (Jakovljevic 2020).

\section{CONCLUSION}

In the first case report, pandemic and restrictive measures were the predisposing factors for suicide attempt of the patient who is the war veteran with diagnosed complex PTSD, while the precipitating factors for the suicide attempt were impaired physician-patient communication, fear of losing a job and existential issues. There is a need to raise awareness in society that rising unemployment is associated with an increased number of suicides, as well as responsible and balanced media coverage of the COVID-19 pandemic.

In the second case report, our patient with bipolar disorder got into relapse of disease with psychotic symptoms during the pandemic of COVID-19 after changes the work structure and after she illegally visited her son who was self-isolated after returning to $\mathrm{B} \& \mathrm{H}$ from abroad, with no self-protected equipment.

Overall, both case studies illustrate the psychological potential that the crisis caused by the COVID-19 pandemic has on at-risk groups of psychiatric patients.

Also, it is obvious that all infected individuals will not die because of the COVID-19 infection, but many persons are suffering additionally because of bad interpersonal relationships. Knowledge, empathy, solidarity, cooperation and unity are the key factors to long-term survival and flourishing of humankind. Let's hope that acquired experiences in the war against corona disease all over the world will be helpful in our spiritual, emotional and social maturation giving us the chance to become better persons, successful in fighting for better public and global mental health. Hopefully COVID-19 pandemic may help humankind to support people living with chronic illness and their loved ones to achieve positive and respectful relationships in perspective of better world.

\section{Acknowledgements: None.}

\section{Conflict of interest: None to declare.}

\section{Contribution of individual authors:}

Nera Hodžić: collecting data, design of the article, drafting the article, review of literature, revising it critically for important intellectual content.

Mevludin Hasanović: collecting data, design of the article, drafting the final version of article and revising it critically for important, intellectual content, review of literature.

Izet Pajević: design of the article, drafting the final version of article and revising it critically for important intellectual content.

\section{References}

1. Bhardwaj V, Angkaw AC, Franceschetti M, Rao R, Baker DG: Direct and Indirect Relationships Among Posttraumatic Stress Disorder, Depression, Hostility, Anger, and Verbal and Physical Aggression in Returning Veterans. Aggress Behav 2019; 45:417-426. doi:10.1002/ab.21827. Epub 2019 Mar 5

2. Brooks KS, Webster RK, Smith LE, Woodland L, Wessely $S$, Greenberg N, Rubin GJ: The psychological impact of quarantine and how to reduce it: rapid review of the evidence. Lancet 2020; 395:912-920. doi:10.1016/S01406736(20)30460-8

3. Cnahg H-C, Huang $K-C$, Chiu $W-C$, Huang $K-C$, Tang $C$ $H$, Su K-P: Change in employement status in bipolar disorder: A longitudinal study using national claims data. J Clin Psychiatry 2016; 77:e429-35.

doi:10.4088/JCP.14m09576

4. Chen Q, Liang M, Li Y, Guo J, Fei D, Wang L, He L, Sheng C, Cai Y, Li X, Wang J, Zhang Z: Mental health care for medical staff in China during the COVID-19 outbreak. Lancet Psychiatry 2020; 7:e15-e16. doi:10.1016/S2215-0366(20)30078-X

5. Duan L, Zhu G: Psychological interventions for people affected by the COVID-19 epidemic. Lancet Psychiatry 2020; 7:300-302. doi:10.1016/s2215-0366(20)30073-0

6. El-Hage $W$, Hingray $C$, Lemogne $C$, Yrondi A, Brunault $P$, Bienvenu T, Etain B, Paquet C, Gohier B, Bennabi D, Birmes $P$, Sauvaget A, Fakra E, Prieto N, Bulteau S, Vidailhet $P$, Camus $V$, Leboyer $M$, Krebs MO, Aouizerate B: [Health professionals facing the coronavirus disease 2019 (COVID-19) pandemic: What are the mental health risks?]. Encephale. 2020 Apr 22. pii:S0013-7006(20)30076-2. doi: 10.1016/j.encep.2020.04.008

7. Fiorillo $A$ \& Gorwood P: The consequencies of the COVID-19 pandemic on mental health and implications for clinical practice. Editorial. European Psychiatry, April 2020, pp. 1-4. doi:https://doi.org/10.1192/eurpsy.2020.35

8. Fisscher M, Coogan AN, Faltraco F, Thome J: COVID-19 paranoia in a patient suffering from schizophrenic psychosis - a case report. Psychiatry Res 2020; 288:113001. doi:10.1016/j.psychres.2020.113001

9. Hasanović M \& Hasanović M: Healing Invisible Wounds Have We Done Enough to Help Sucidal War Veterans Who Suffer from PTSD. Psychiatr Danub 2020; 32:135136. PubMed PMID: 32303049

10. International Labor Organization: Almost 25 million jobs could be lost worldwide as a result of COVID-19, says ILO. https://www.ilo.org/global/about-the-ilo/newsroom/ news/WCMS_738742/lang-en/index.htm Date: March 18, 2020 Date accessed: March 24, 2020

11. Jakovljević M: The Placebo-Nocebo Response in Patients with Depression: Do we Need to Reconsider our Treatment Approach and Clinical Trial Designs? Psychiatr Danub 2014; 26:92-95

12. Jakovljevic M: COVID-19 Crisis as a Collective Hero's Journey to Better Public and Global Mental Health. Psychiatr Danub 2020; 32:3-5. doi:10.24869/psyd.2020.3. PubMed PMID: 32303022

13. Jakovljevic M, Bjedov S, Jaksic N, Jakovljevic I: COVID19 Pandemia and Public and Global Mental Health from the Perspective of Global Health Securit. Psychiatr Danub 2020; 32:6-14. doi:10.24869/psyd.2020.6.

PubMed PMID:32303023 
14. Kang HK, Bullman TA, Smolenski DJ, Skopp NA, Gahm GA, Reger MA: Suicide risk among 1.3 million veterans who were on active duty during the Iraq and Afghanistan wars. Ann Epidemiol 2015; 25:96-100

15. Kawahol W, Nordt C: COVID-19, unemployment, and suicide. Lancet Psychiatry 2020; 7:389-390. doi:10.1016/S2215-0366(20)30141-3

16. Laxman KE, Lovibond KS, Hassan MK: Impact of bipolar disorer in employed populations. Am J Manag Care 2008; 14:757-64

17. Maguire PA, Reay RE, Looi JC: A sense of dread: affect and risk perception in people with schizophrenia during an influenza pandemic. Australas Psychiatry 2019; 27:450-455. doi:10.1177/1039856219839467

18. Maguire PA, Reay RE, Looi JC: Nothing to sneeze at uptake of protective measures against an influenza pandemic by people with schizophrenia: willingness and perceived barriers. Australas Psychiatry 2019; 27:171178. doi:10.1177/1039856218815748

19. Marčinko D, Jakovljević M, Jakšić N, Bjedov S, Mindoljević Drakulić A: The importance of psychodinamic approach during COVID-19 pandemic. Psychiatr Danub 2020; 32:15-21 https://doi.org/10.24869/psyd.2020.15

20. McGabe R, Healey PGT: Miscommunication in DoctorPatient Communication. Top Cogn Sci 2018; 10:409-424. doi:10.1111/tops. 12337

21. Mindoljević Drakulić A, Radman V: Crisis psychodrama in the era od COVID-19. Psychiatr Danub 2020; 32:22-24. https://doi.org/10.24869/psyd.2020.22
22. Ministry of Civil Affairs of Bosnia and Herzegovinal Ministarstvo civilnih poslova Bosne i Hercegovine: 2020. http://mcp.gov.ba/publication/read/sluzbene-informacijeo-koronavirusu-covid-19 (Approached 22.5.2020)

23. Nordt C, Warnke I, Seifritz E, Kawohl W: Modelling suicide and unemployment: a longitudinal analysis covering 63 countries, 2000-11. Lancet Psychiatry 2015; 2:239-245

24. Olfson M, Blanco C, Wall M, Liu SM, Saha TD, Pickering RP, Grant BF: National Trends in Suicide Attempts Among Adults in the United States. JAMA Psychiatry 2017; 74:1095-1103

25. Pellecchia U, Crestani R, Decroo T, Van den Bergh R, AlKourdi Y: Social consequences of Ebola containment measures in Liberia. PLoS One 2015; 10:e0143036

26. Shuja KH, Aqeel M, Jaffar A, Ahmed A: COVID-19 Pandemic and Impending Global Mental Health Implications. Psychiatr Danub 2020; 32:32-35. doi:10.24869/psyd.2020.32. PubMed PMID: 32303027

27. Street RL Jr, Gordon H, Haidet P: Physicians' communication and perceptions of patients: is it how they look, how they talk, or is it just the doctor? Social Science \& Medicine 2007; 65:586-598. doi: 10.1016/j.socscimed.2007.03.036

28. U.S. Department of Veterans Affairs: State Data Sheets, 2016. www.mentalhealth.va.gov Accessed March 17, 2019

29. Wilks CR, Morland LA, Dillon KH, Mackintosh M-A, Blakey SM, Wagner HR: VA Mid-Atlantic MIRECC Workgroup; Elbogen EB. Anger, Social Support, and Suicide Risk in U.S. Military Veterans. J Psychiatr Res 2019; 109:139-144. doi:10.1016/j.jpsychires.2018.11.026. Epub 2018 Dec 4

Correspondence:

Prof. Mevludin Hasanović, MD, PhD

Department of Psychiatry, University Clinical Center Tuzla Rate Dugonjića b.b., 75000 Tuzla, Bosnia and Herzegovina E-mail:dr.mevludin.hasanovic@gmail.com 